\title{
Entre dores e encontros: sobre a produção de narrativas das mulheres do ambulatório de oncologia clínica da Unicamp
}

\author{
Maycon Leandro da Conceição ${ }^{1}$
}

\section{Resumo}

A partir do estudo etnográfico (2018) realizado no ambulatório de oncologia, a pesquisa analisa os discursos do cuidado em saúde. Partirmos da pergunta: quais discursos acionados pelas mulheres em tratamento oncológico e que se relacionam com os saberes objetivos e subjetivos das configurações de gênero e cidadania presentes nas políticas de saúde? Para tal, a metodologia de entrevistas semiestruturadas com profissionais, familiares e observação participante com as mulheres no HC-UNICAMP. Após o mapeamento dos discursos, a categorização dos discursos encontrados ocorreu com a abordagem de Análise de Conteúdo. Essas mulheres precariamente a partir de suas experiências e (des)subjetivação do adoecimento criam estratégias micropolíticas das complexas relações da dimensão de gênero, por desafios cotidianos. Por fim, a pesquisa das biografias, mas sobre as relações identitárias que marcam individualidades, trazem em si identificações, seja para potencializar a autonomia ou enunciações reflexivas das normatividades biomédicas que reduzem a subjetividade em corpos doentes.

Palavras-chave: políticas públicas de saúde; gênero; cidadania.

\footnotetext{
1 Mestrando em Ciência Política-Programa de Pós-Graduação em Ciência Política (PPGPol-UFSCar), e-mail mayconleandro04@hotmail.com

GT 06 - Gênero, cuidado e políticas de saúde
} 


\title{
Between pains and meetings: on the production of narratives of women from the clinical oncology outpatient clinic of Unicamp
}

\begin{abstract}
Based on the ethnographic study (2018) carried out at the oncology outpatient clinic, a study analyzes the discourses of health care. Starting from the question: which discourses triggered by women undergoing cancer treatment and which relate to the objective and subjective knowledge of gender and citizenship configurations present in health policies? For this, the semi-structured classification methodology with professionals, family members and participant observation with women at HC-UNICAMP. After mapping the speeches, a categorization of the speeches found occurred with a Content Analysis approach. These women precariously from their experiences and subjectivation of the micropolitical criamological illness of the complex relations of the gender dimension, due to daily challenges. Finally, researching biographies, but on the identity relationships that mark individualities, bring with them identifications, whether to enhance autonomy or reflective enunciations of biomedical norms that affect subjectivity in sick bodies.
\end{abstract}

Keywords: public health policies; gender; citizenship.

\section{Introdução}

A saúde das pessoas é um assunto ligado às próprias pessoas. Esta ideia é primordial e fundamental, não se pode substituir os atores da saúde por elementos externos (...) é cada indivíduo quem sofre e reconhece suas dificuldades para enfrentar as demandas que seu meio lhe impõe (DEJOURS, 1986. )

A epígrafe apresentada acima analisa diferentes abordagens que podem relacionar as práticas objetivas e subjetivas do tratamento oncológico e o percurso de uma cidadania plena, palavras que contam com um vasto rol de significados possíveis. Sendo associado o "estar com câncer" como resultado de uma doença que continua sendo estigmatizante, pois é automaticamente associada com a morte. 
(CANESQUI, 2007). Logo, esta pesquisa analisa a relação desenvolvida, por exemplo, em função especificamente das usuárias de serviços de saúde para o exercício de seus direitos de cidadania, igualdade, justiça e à participação social, ou, ainda, em função dos novos desafios cotidiano de uma saúde integral, a partir de um tratamento humanizado e promoção de saúde, têm configurado novas possibilidades de vida e expressão para uma nova concepção de rearranjos micropolíticos e marcadores sociais como gênero, no qual apresenta o direito de saúde no Sistema Único de Saúde (SUS), mas principalmente como instrumento de emancipação social: "Temos o direito a ser iguais quando a diferença nos inferioriza, temos o direito a ser diferentes quando a igualdade nos descaracteriza" (CHAUÍ; SANTOS. BS, 2016).

Outro argumento possível de relacionar os dois vocábulos teórico é de adotar a cidadania como prisma fundamental de responsabilidade dos direitos individuais e responsabilidade coletiva frente à regulação da figura do Estado. Para essa análise, a expressão do direito à saúde reportar-se no artigo $196^{\circ}$, constituem "a saúde é direito de todos e dever do Estado, garantindo mediante políticas sociais e econômicas que visem à redução de risco de doenças e de outros agravos e ao acesso universal e igualitário às ações e serviços para suas promoção, proteção e recuperação". Já um significado mais específico da cidadania, pode-se ser sintetizado na seguinte argumentação: o vínculo de pertencimento do indivíduo à sociedade contemporânea e assegurado no pacto documental de cunho político como na Constituição Federativa de 1988. Ou seja, no artigo 1º, inciso II, afirma que a República Federativa do Brasil, constituída em Estado Democrático de Direito e têm a cidadania como um dos seus pilares. A expressão da cidadania também é apresentada no inciso XXXIV, LIV, LXXI e LXXVII do artigo $5^{\circ}$, ao afirmar que "conceder-se á mandado de injunção sempre que falta de norma reguladora torne inviável o exercício dos direitos e liberdade constitucionais e das prerrogativas inerentes a nacionalidade, à soberania e à cidadania. 
Isto posto, a imersão no campo ocorreu no período de abril a dezembro de 2018, neste curto intervalo de pesquisa, eu ainda não havia me atentado para o fato de estar iniciando um trabalho que ampliaria meus conhecimentos teóricos e práticos na posição geracional, produção de cuidado, questões raciais, de gênero e de classe. E, principalmente, que aquele campo me ensinaria e muito reflexões para além dos saberes biomédicos, compreensão de estar no limite entre meus estranhamentos, incômodos, questionamentos e, só assim, acostumá-lo com à silhueta dos "corredores, dores e odores" e logo depois, adaptar meu olhar etnográfico, por meio do qual se ilumina realidades e passa-se a identificar através de um encontro entre um pesquisador e as usuárias a oportunidade de discursos em primeira pessoa. A pesquisa realizouse através do Programa de Aprimoramento de Ciências Sociais em Saúde sob responsabilidade da Faculdade de Ciências Médicas da Unicamp no período de 2018.

Aqui, gostaríamos de ressaltar a importância de analisar os discursos das mulheres em tratamento de quimioterapia e/ou radioterapia e a importância de adotar a palavra usuárias de saúde, para evitar o uso de "pacientes" que é uma normatização dos saberes biomédicos que insistem em reduzir a subjetividade dos indivíduos só a corpos doentes. $\mathrm{O}$ discurso aparece na reflexão de Michel Foucault como objeto de estudo, porque seu objetivo é conhecer o que torna este ou aquele discurso possível, ou seja, porque determinados discursos são aceitos como verdadeiros e não outros em seu lugar. Ou seja, "não há saber sem uma prática discursiva definida, e toda prática discursiva pode definir-se pelo saber que ela forma" (FOUCAULT, 2005, p. 205). O discurso é instrumento de poder quando possibilita seu exercício e é seu efeito quando é produzido por ele. Enfim, para o intelectual é o espaço aonde vão se consolidar o saber e o poder. Nesse sentido a construção do câncer tratou-se sempre com um estigma ligado a morte.

Por fim, a partir de um estudo etnográfico (2018) em Campinas, esta pesquisa propõe-se discutir o campo da Ciência Política, recortando-o a partir da exigência, intrínseca desse campo, de situar-se 
em relação além dos saberes biológicos. Destaca o modo das Ciências Sociais tratam as questões dos atores como portadores de direitos, justiça e participação social e principalmente a relação do Estado em formular políticas públicas de saúde. Logo, consideramos o protagonismo das mulheres no Ambulatório de Oncologia.

O Hospital de Clínicas da Unicamp inaugurado em 1963 é na atualidade um dos maiores hospitais gerais públicos do Estado de São Paulo. O atendimento ambulatorial de oncologia clínica possui serviços de equipe médica, enfermagem, nutricionista, psicologia clínica e farmácia. Nesse cenário etnográfico é válido notar que é composto por sua grande maioria por homens, já que dentro da Universidade Estadual de Campinas existe um hospital destinado ao atendimento para as mulheres, o Centro de Atenção Integral à Saúde da Mulher (CAISM). Por ser um hospital de referência nacional, dentro do sistema SUS, as pessoas preferem vir ao município de Campinas e ter certeza de um diagnóstico preciso e de tratamento de qualidade, ao permanecer em suas cidades: "A Unicamp é referência na minha vida, vejo pessoas com planos de saúde brigando para serem atendidos aqui (...) eu saio da consulta médica com encaminhamento de todos os exames, se eu ficasse na minha cidade, com certeza já teria morrendo" (usuária).

\section{Construção do problema de pesquisa e abordagem teórico- metodológica}

Esta pesquisa propõe analisar a cidadania na constituição atual do campo da saúde oncológica brasileira. Tendo como objetivo adaptar um olhar crítico para as políticas públicas sob a perspectiva da realidade das mulheres em tratamento oncológico ou acompanhamento em caso de remissão. Para melhor precisar o argumento, faz-se necessário ressaltar alguns aspectos da abordagem teórico-metodológica escolhida, trata-se um uma pesquisa de abordagem qualitativa etnográfica e a coleta de dados se realizou com entrevistas semiestruturadas com funcionário, familiares e observação participante 
de caráter etnográfico com as mulheres do serviço oncológico, sobretudo nas salas de esperas, oficina da beleza e acompanhamento no serviço de assistência social no próprio ambulatório clínico, todos vinculados sob a responsabilidade do Hospital de Clínicas da Unicamp.

Sobre a importância das entrevistas semiestruturada, para a condução da pesquisa com os funcionários e familiares do ambulatório irei me basear no método de aplicação de entrevistas. Embora a coleta de dados realizou com um roteiro de entrevistas , não desconsideramos também a modalidade "não diretiva" , ou seja, baseada no discurso livre, que permite ao funcionários e familiares uma expressão mais clara de sua experiência, que é proveniente da abordagem clínica sobre o cuidado de saúde mental e percepção de cidadania e requer que o pesquisador mantenha uma escuta ativa e com atenção receptiva a todas as informações prestadas (CHIZZOTI, 1991).

A relevância da abordagem das entrevistas ficará evidente quando enfocamos as experiências dos atores sociais permitindo, tal como proposto pelos estudos no campo da saúde, entender os processos de "saúde - doença" como experiências repletas de significados. Também constituímos a observação participante em todos os espaços no serviço oncológico clinica, trazendo sua contribuição considerando o contexto de redirecionamento e uma nova concepção de assistência psiquiátrica baseada não mais na doença, mas que pretende valorizar a experiência dos sujeitos e se aproximar dos mesmos através de uma escuta ativa.

Já a observação participante de caráter etnográfico com as usuárias, é um "método qualitativo de pesquisa que visa à descrição e o entendimento abrangente de fenômenos culturais presentes em grupos, comunidades ou instituições particulares de acordo com os próprios termos e atitudes daqueles que os vivenciam em seu cotidiano" (SOUZA, 2014, p. 308). Seu enfoque é, portanto, a perspectiva dos atores sociais e, para tanto, deve combinar um detalhado trabalho de campo, um processo minucioso de descrição da experiência estudada e um 
processo de interpretação/tradução convertido em texto no qual os dados obtidos medeiam a relação entre as teorias e o campo (GUBER, 2001).

Após o levantamento de dados a partir das entrevistas semiestruturadas e da observação participante. Partirmos para a análise dos principais argumentos discursivos dos funcionários, usuárias de saúde e familiares. As transcrições das entrevistas semi-estruturada e diário de campo será realizada a partir da utilização do software MAXQDA, sendo uma ferramenta de análises de dados qualitativos e métodos mistos de pesquisa. Nesse sentido, essa dissertação pretende basear em um conjunto de procedimentos: pré-análise da bibliografia corresponde ao tema da pesquisa; exploração do material; organização e interpretação da coleta de dados (BARDIN 2009; BARDIN 2016).

\section{Discussão de Resultados}

A partir de um estudo etnográfico (2018) com mulheres na oncologia, vinculado ao Hospital de Clínicas da UNICAMP, CampinasSP. O ambulatório clínico é destinado para realizações de quimioterapia e/ ou radioterapia e conta com a participação de uma equipe multidisciplinar como, enfermeiros, técnicos de enfermagem, psicólogos, médicos oncologistas, assistentes sociais, farmacêuticos e com a presença diária de alunos da Faculdade de Ciências MédicasUnicamp. Todos esses serviços prestados estão ligados ao um tratamento humanizado e com promoção de saúde e pautado nas condições sociais e econômicas das mulheres que visem uma expansão de cidadania plena. Ademais, os dados obtidos da pesquisa com auxílio do MAXQDA indicam três categorias de análise: 1 . Subjetividades de estar com câncer e (re)construções das identidades; 2. Impasses das mulheres para a garantia de direitos à saúde e estigmatização do câncer no cotidiano; 3. Preocupações atuais orçamentárias do SUS, especial com o congelamento de gastos e dificuldades de garantir os direitos 
previdenciários, como auxílio de doença e até mesmo aposentadorias decorrido ao agravamento da doença.

O cuidado em saúde não é apenas um procedimento técnico simplificado, mas uma ação integral e humanizada que tem significados e sentidos voltados para compreensão em saúde como o direito do indivíduo. Esse aspecto considera e respeita as diferenças das pessoas e as necessidades específicas de cada subjetividade, quando ampliamos as perspectivas do cuidado em saúde através dos enfretamentos diários percebemos os múltiplos rearranjos de percepções da realização de tratamento contra o câncer. O processo de saúde-doença é associado à prática de hábitos saudáveis na literatura do campo da saúde, percebese que o autocuidado envolve uma complexidade ainda maior, relacionado ao modo de existir de cada um no mundo, suas reflexões, crenças, julgamentos, atitudes, gostos, valores e hábitos, representação sobre saúde, trajetórias de vida, suas experiências anteriores, o momento presente adoecimento. Em síntese, o autocuidado pode ser entendido como todas as práticas desenvolvidas pelo próprio sujeito em seu benefício para promover, preservar, assegurar e manter a vida.

A palavra medo foi a palavra que mais ouvi dos informantes durante nossa imersão na sala de espera e nas oficinas da beleza. Esse substantivo foi a síntese dos sentimentos que percorriam o universo dos usuários dos serviços oncológicos: a angústia e o medo do câncer porque está associado com uma doença grave, sofrimento, morte e incertezas sobre o tratamento. No estudo de Silveira o medo também foi referido: $\mathrm{O}$ medo vivido como prenúncio da morte e do sofrimento é associado ao rótulo da doença e se faz presente nos relatos de praticamente todos os informantes. [...] Tanto a vulnerabilidade física, quanto a imprevisibilidade da doença mantêm presente a sensação de medo originada pelo diagnóstico (SILVEIRA, 2002, p. 373). Nas primeiras incursões pelo hospital as mulheres referem-se uma insegurança, por vários motivos, mas em geral associados ao medo em relação as incertezas com o futuro: "Cheguei aqui pela primeira vez e tudo me assustava, eu era muito nova, com 38 anos e com um menino, 
era só nós dois e pensei e agora! Gente será que ficarei assim, tenho um filho menor de idade e não posso morrer" (usuária).

A incerteza sobre o futuro, sobre os desdobramentos de sua vida e sobre a talvez impossibilidade de realizar seus projetos de vida, somase à necessidade de pensar em estratégias no gerenciamento do adoecimento na vida cotidiana. Muitas das vezes, o medo e o pânico vão surgir quando as mulheres têm a certeza do diagnóstico, nesse momento a doença sai do campo imaginário, das possibilidades e passa a ser real: Eu não imaginava que seria paciente daqui ,você imagina que acontecerá no telhado do vizinho e não no seu (...) eu demorei muito para aceitar que estava com câncer. (usuária).

As oficinas da beleza são atividades grupais que promovem maior integração social, a expressividade, o desenvolvimento de habilidades corporais, a realização de atividades e o exercício coletivo de cidadania. A automaquiagem pode ser utilizada como instrumento potencializador desse processo, ampliando a percepção, resgatando a autoestima e despertando a criatividade das usuárias no ambulatório. Mas exista uma certa ambivalência, já que o ambulatório é frequentando por sua maioria por homens e ainda não exista atividades de oficinas destinados para eles. A oficina é um local privilegiado no qual as mulheres compartilham a sua doença. É o único espaço não medicalizado do ambulatório. Nesse ambiente as mulheres se sentem à vontade para conversarem os mais diferentes assuntos e trocar informações sobre as falas e os tratamentos médicos. É um local onde se formam laços de afetividade e amizade, e, mais ainda, dividem suas experiências e expectativas.

A categoria de identidade é esclarecida por Hall (2000) como uma construção social produzida no discurso e definida com base em critérios culturais, históricos e institucionais que buscam criar uma imagem do sujeito, pensada como estável. É o ponto entre práticas e discursos que convocam os sujeitos para que assumam seus lugares como produtos e produtores de discursos e processos que produzem 
subjetividades. Já para Levi-Strauss a identidade visa aprofundar as relações entre os indivíduos e a sociedade, em um processo de ação e interação entre "espelhos e máscaras" a interação estruturada, ou seja, é individual e social e justifica nas subjetividades cotidianas das mulheres e relações sociais.

Durante as entrevistas nas salas de espera é notório em observar - a expectativa do diagnóstico, depois de se fazer exames, consultas médicas, dentre tantos outros procedimentos para a confirmação da doença, promovem nas pessoas a consciência da possibilidade da morte e até mesmo durante o tratamento. Entretanto, compreendemos que o impacto do câncer, depende muito mais de fatores sociais, culturais e econômicos do que necessariamente das consequências biológicas. A sala de espera, enquanto lugar de conversa entre os pacientes, acompanhantes e de troca de informações sobre a doença, estão impregnadas de estigmas sobre o câncer. O estudo de Silveira teve essa percepção:

As salas de espera e a Central de Quimioterapia são alguns dos lugares onde é observado que, enquanto aguardam, pacientes e familiares conversam entre si, trocam informações e fazem comentários sobre a doença. Como normalmente as pessoas com maior contato institucional são os doentes de maior gravidade, muitas das histórias que circulam neste cenário são repletas de sofrimento e de todo tipo de dificuldades que os pacientes enfrentam. Ou seja, é o próprio cenário clínico que alimenta o imaginário associado ao câncer (SILVEIRA, 2002, p. 370).

Outra observação muito importante em relação a sala de espera é sobre os jalecos brancos da equipe médica e estudantes, que funciona como marcadores de poder institucional, subjetividades ou até mesmo como higienização. A noção de roupa, tal como é discutida por Viveiros de Castro (2002), seria a forma manifesta dos seres, um atributo que pode vir a ser trocado e descartado. Tal ideia faz supor que tal roupa envolva um corpo, porém o autor esclarece que aquilo que a roupa envolve não tem uma qualidade fixa. $O$ interior da roupa não é uma 
substância, mas estaria preenchido por intencionalidades, subjetividades que, acionadas pela roupa, se "materializam" nos corpos desta ou daquela maneira.

O conceito de cidadania no Plano Nacional de Atenção Oncológica são termos cujo conteúdo semântico é extremamente amplo. Assim, os conceitos também poderão ser abordados sob a ótica da assunção da saúde como elemento essencial à perpetuação da figura ou da posição especial do direito à saúde como exercício do direito à cidadania. Sendo assim, a cidadania é o sentimento de nacionalidade comum, relacionado a uma ordem de igualdade de direitos. Segundo Marshall na obra Cidadania, classe social e status (1967), o elemento civil é o conjunto de direitos relativos à liberdade de expressão, pensamentos, de crenças, direito à propriedade e jurisdicional. Já o elemento político equivaleria ao direito de participação, tomando a vontade individual para sua composição através do voto. O elemento social é composto, pelos direitos sociais: do direito à saúde, aos previdenciários, garantia aos indivíduos e à comunidade segundo concepção de dignidade humana, ou seja, pelo bem-estar.

Durante a minha observação no ambulatório mostrou-se relatos sobre a necessidade de orientação para conseguirem auxílio doença e aposentadoria, são constantes em seus discursos e, consequentemente a burocracia, protela ainda mais o sofrimento dos usuários:

O INSS pede que você leve todos os seus exames desde o início do tratamento atualizados. Você tem uma pasta desse tamanho de xerox e acho que não vale nada para eles. Deixei na recepção da previdência. Aí eu voltei lá depois de 40 dias sem nenhum centavo no bolso, com todas as contas atrasadas (...) tinha nada no bolso e mesmo assim minha aposentadoria foi negada e eu não conseguia voltar ao trabalho. (usuária) 


\section{Conclusão}

Esta pesquisa mostrou-se a importância de um estudo onde precisa valorizar o encontro com o outro, sendo esses sujeitos e sobretudo mulheres produtoras legítimos de sabedorias práticas. Almejamos com a pesquisa utilizar a escuta como instrumento de produção de cuidado das mulheres em tratamento oncológico. Procuramos valorizar a autonomia das usuárias, através das experiências vividas, a sua dinâmica de vida, que são importantes para compreender o processo de expansão da cidadania. Interessa-nos, portanto, que todo sujeito precisa ter o suporte humanizado ao ambulatório. Suporte sensível, atento, respeitoso, presente, coadjuvante, acessível, conectado. Uma observação participante fisicamente próxima quando necessário, respeitosamente distante quando desejado. E tendo como ponto de vista o estranhamento de um cientista político fazendo pesquisa numa cartografia exclusivamente dominada pelos saberes da biomedicina.

Através dos discursos das mulheres, mostrou-se que a percepção do adoecimento não é singular, cada indivíduo vivência de uma forma distinta. A própria concepção de câncer, ao longo do tempo, não é única ou linear, produzem múltiplas formas de enfrentamento e significados. Ela muda, flutua, apresenta novos desafios no cotidiano. Uma doença é uma transformação na vida, mas também há transformações na doença. Ou seja, a saúde pode ser pensada como possibilidade de ficar doente e poder se recuperar (CANGUILHEM, 1990, p. 26). Interessar-me, portanto, que todo sujeito precisa ter o suporte humanizado no ambulatório.

Interessamos o campo científico no ambulatório é, portanto, um "universo no qual estão inseridos os agentes e as instituições que produzem, reproduzem ou difundem os artefatos do campo. Esse universo é um mundo social como os outros, mas que obedece a leis sociais mais ou menos específicas" (BOURDIEU, 2004, p. 20). Ou seja, o campo da política pública de saúde é complexo, marcado por relações 
de poder instituídas pelos domínios biomédicos, constituído por disputas e divergências, tanto em sua mecânica interna, como em sua relação político e cultural com a sociedade civil.

Constatamos que os usuários promovem as mudanças em suas vidas e não a doença. $\mathrm{O}$ adoecimento gera $\mathrm{o}$ momento da adaptação/recusa e a possibilidade de fazer tratamentos combinatórios, como por exemplo, a busca de alívio, escolha só do tratamento de cuidados paliativos e explicações pela religião e pela fé, ou ainda, os discursos para além dos saberes biomédicos. Para algumas mulheres, não tratar uma determina doença é a escolha consciente e pessoal decorridos ao agravamento do câncer. Porém, estão sujeitas a estigmatização (GOFFMAN, 1980). Por fim, observou-se também que o Sistema Único de Saúde-SUS foi definido por muitos usuários como sendo um sistema "por favor" e não por direito; isto significa que todas as ações que são tomadas por esse sistema de saúde são para as pessoas sem recursos e, por isso, realizadas de maneira precária em suas cidades de origens.

\section{Referências}

BARDIN, L. Análise de Conteúdo. Lisboa, Portugal: Edições 70, LDA, 2009.

BARDIN, L. Análise de Conteúdo. São Paulo: Edições 70 Brasil, 2016.

BOURDIEU, P. Para uma sociologia da ciência. [Science de la science et refléxivité]. Pedro Elói Duarte (Trad.). Lisboa: Edições 70, 2004

BRASIL. Constituição da República Federativa do Brasil, 1988.

CANESQUI. AM. Estudos antropológicos sobre os adoecidos crônicos. In: CANESQUI, A. M. (org.). Olhares socioantropológicos sobre os adoecidos crônicos. São Paulo: Hucitec, 2007. p.19-51.

CANGUILHEM, G.O. Normal e Patológico. Rio de Janeiro: Editora Forense Universitária, 1990. 
CHIZZOTTI, A. Pesquisa em ciências humanas e sociais. São Paulo: Cortez, 1991

DEJOURS, C. Por um novo conceito de saúde. Revista Brasileira de Saúde Ocupacional, n. 1, p. 2-15, 1986.

FOUCAULT, M. Arqueologia do Saber. 7. ed. Tradução Luiz F.B. Neves. Rio de Janeiro: Forense Universitária, 2005.

GUBER, R. La etnografía, método, campo y reflexividad. Bogotá: Grupo Editoria, 2001.

GOFFMAN, E. Estigma - notas sobre a manipulação da identidade deteriorada. 3. ed. Rio de Janeiro: Zahar, 1980

HALL, Stuart; WOODWARD, Kathryn. Identidade e diferença: a perspectiva dos estudos culturais. Petrópolis: Vozes, 2000.

MARSHLL, A. Cidadania, classe social e status. Rio de Janeiro: Zahar,1967.

SANTOS, Boaventura de S.; CHAUÍ, Marilena. Direitos humanos, democracia e desenvolvimento. São Paulo: Cortez, 2013.

SILVEIRA NH. Câncer e Morte. Revista Brasileira de Sociologia da Emoção, v. 1, n. 3, p. 366-376, 2002.

SOUZA, M.R. Uma questão de método: origens, limites e possibilidades da etnografia para a psicologia social. Psicologia USP, v. 25, n. 1, p. 307316, 2014.

VIVEIROS DE CASTRO, Eduardo B. 2002. A Inconstância da Alma Selvagem e Outros Ensaios de Antropologia. São Paulo: Cosac \& Naify. 